\title{
Poder, discursos e práticas políticas: Processos de mediação em um Centro de Atenção Psicossocial em Araraquara
}

Power, discourses and political pratices: Mediation processes in a psychosocial care center in Araraquara

Luiz Ricardo de Souza Prado

\section{(2) OpenEdition Journals}

\section{Edição electrónica}

URL: http://journals.openedition.org/aa/5841

DOI: 10.4000/aa.5841

ISSN: 2357-738X

\section{Editora}

Programa de Pós-Graduação em Antropologia Social (UnB)

\section{Edição impressa}

Paginação: 93-108

ISSN: 0102-4302

\section{Refêrencia eletrónica}

Luiz Ricardo de Souza Prado, «Poder, discursos e práticas políticas: Processos de mediação em um Centro de Atenção Psicossocial em Araraquara», Anuário Antropológico [Online], v.45 n.2 | 2020, posto online no dia 27 maio 2020, consultado o 27 abril 2021. URL: http://journals.openedition.org/aa/5841 ; DOI: https://doi.org/10.4000/aa.5841

\section{(c) (i) (9)}

Anuário Antropológico is licensed under a Creative Commons Atribuição-Uso Não-Comercial-Proibição de realização de Obras Derivadas 4.0 International. 


\title{
Poder, discursos e práticas políticas: processos de mediação em um Centro de Atenção Psicossocial em Araraquara
}

\author{
Power, discourses and political pratices: \\ mediation processes in a psychosocial care center in Araraquara
}

DOI: https://doi.org/10.4000/aa.5841

\section{Luiz Ricardo de Souza Prado • Secretaria de Educação do Estado de São Paulo - Brasil}

Mestre em Ciências Sociais pelo Programa de Pós-graduação em Ciências Sociais da Universidade Estadual Paulista "Júlio de Mesquita Filho", Faculdade de Ciências e Letras de Araraquara. Atualmente, é professor da Secretaria de Educação do Estado de São Paulo e membro do Grupo de Estudos e Pesquisa em Antropologia Contemporânea (GEPAC/FCLAR/UNESP).
ORCID: $\odot 000-0002-8611-4724$ luizricardoprado@outlook.com
Este artigo tem por objetivo analisar os impactos das atuais políticas de saúde mental no Brasil nas práticas e discursos dos chamados familiares de usuários de um serviço de atenção psicossocial. Foi realizada etnografia no Centro de Atenção Psicossocial (CAPS) II de Araraquara - interior de São Paulo -, com foco nos grupos de familiares e nas reuniões diárias da equipe técnica dos profissionais. Por meio da teoria da mediação cultural de Montero (2005), procura-se entender de que forma o envolvimento com este tipo de serviço de saúde mental produz mudanças nas práticas e discursos dos agentes ali atendidos. Foi observado que a participação na instituição propicia o pensar de relações sociais em termos médicos apor estes familiares, que ressignificam a conduta socialmente indesejável dos usuários como doença mental. Dessa forma, nossos resultados apontam que a participação destes chamados familiares no CAPS II resulta em uma tradução do projeto ético-político da instituição a seus contextos locais, de modo a modificar ou reproduzir suas práticas e discursos de acordo com suas condições de possibilidade e desejos de cuidado.

CAPS. Mediação cultural. Familiares. Políticas em saúde mental.
The present paper aims to analyze the impacts of the currents public mental health policies in Brazil upon the discourses and practices of the so-called relatives of the users from a psychosocial attention service. We have made ethnography in the Araraquara's Psychosocial Attention Center (CAPS) II between families groups and in the daily reunions of the professionals. Using the theory of intercultural mediation from Montero (2006), we aim to understand how the involvement with this kind of service changes the practices and discourses of the social agents there present. As results, we've observed that the attendance at the institution foment the possibility to think about social relations in medical terms by the relatives, who ressignify the users' social undesirable behaviors as mental illness, applying what is lived in the mental health service to the their local contexts. Our result points that the participation of the so-called relatives in the CAPS II translates the ethical-political project of the institution to their local contexts changing or reproducing practices and discoursers accordingly to their possibilities and care demands.

CAPS. Cultural mediation. Relatives. Mental Health Policies. 


\section{Introdução}

Enquanto política de desinstitucionalização ${ }^{2}$ do atendimento em saúde men$\mathrm{tal}^{3}$, os Centros de Atenção Psicossocial oferecem tratamento médico e psicoterápico aos seus usuários sem fazer uso de longas internações, ao mesmo tempo em que fortalecem os vínculos da pessoa com transtorno mental ${ }^{4}$ grave com seu contexto social de existência. Para isto, os CAPS oferecem o chamado grupo de familiares, uma reunião feita com os familiares dos usuários da instituição para discutirem sobre suas vivências cotidianas, no intuito de aproximá-los do tratamento oferecido.

Entretanto, sabe-se que, no Brasil, a medicina oficial foi pouco garantida às camadas mais pobres e marginalizadas da população, fazendo com que o discurso médico tivesse grande dificuldade de penetrar nos estratos sociais mais baixos, que recorriam a práticas de curas religiosas e a saberes não eruditos, como mostram os trabalhos de Montero (1985) e Loyola (1984). Autores como Duarte (1986) e Cardoso (1999) salientam o papel central ocupado pela categoria "nervoso" nos discursos e representações dessas populações, em que os nervos - entendidos enquanto uma estrutura moral e corpórea dos sujeitos e responsável por mediar suas relações com o contexto social - aparecem como uma representação que organiza a experiência da subjetividade e do mal-estar, mais do que um "eu" unitário e psicologizado como preconizado pelas ciências como psiquiatria e psicologia.

Partindo desse contexto em que uma população distante das práticas e saberes da medicina oficial passa a frequentar uma instituição de assistência psiquiátrica, mediante uma política pública que visa incluir estes sujeitos enquanto participantes ativos em sua construção, este trabalho busca entender como ocorre o processo de inculcação das categorias de transtorno mental utilizadas por agentes do Estado na população que agora é alvo desta política. Para isso, recorremos à teoria da mediação intercultural de Montero (2006), a qual procura analisar como se processa o jogo dialógico entre agentes sociais de universos simbólicos distintos, que possibilitem a construção de um campo de práticas e representações compartilhadas - o que não exclui a existência de assimetrias de poder.

Este trabalho tem por objetivo analisar como os familiares dos usuários se apropriam das terapêuticas e saberes oferecidos pelo CAPS, procurando apreender se a vivência na instituição modifica suas práticas e discursos em saúde mental. Procura-se, por meio de uma análise através da teoria da mediação cultural, apreender a relação entre saberes e práticas sociais, além de observar como se processa, de forma concreta, uma política pública de saúde mental que tem como objetivo promover um processo de desinstitucionalização do atendimento. Para analisar este contexto, participei três vezes por semana dos grupos de familiares - num total de 30 reuniões - acompanhando-as entre janeiro e julho de 2018, assim como de 20 das reuniões diárias dos técnicos do CAPS II da cidade de Araraquara. Além disso, realizei entrevistas com três familiares de usuários para apreender como os saberes e práticas veiculados na instituição eram apropriados em seus contextos locais de existência.

O presente trabalho foi aprovado no Comitê de Ética em pesquisa da UNESP/
1 O presente trabalho é derivado da dissertação de mestrado intitulada Micropolíticas e processos de mediação no atendimento psicossocial: 0 CAPS II de Araraquara, defendida em março de 2019.

2 Por desinstitucionalização entende-se a mudança das políticas públicas em saúde mental que passam do foco de internação em hospitais psiquiátricos para um novo foco em atendimentos das pessoas portadoras de transtornos mentais graves de forma comunitária, sem exclusão de seus contextos locais, com pouco ou nenhum recurso a períodos de internação.

3 Para uma descrição mais minuciosa do histórico da reforma psiquiátrica e da desinstitucionalização do atendimento psiquiátrica no Brasil, confira Amarante (1995).

4 Como aponta Foucault (1975), a loucura enquanto patologia surge através de um processo histórico que culmina no momento em que a racionalidade é entendida como condição natural do homem e, por isso, aqueles que não a exercem precisam de tratamento médico. Ainda que instituições como o CAPS surjam como resposta a políticas públicas que entendiam a loucura a partir de uma olhar positivista, foi possível observar em minha etnografia a presença de certa tensão entre os saberes biomédicos e as formas psicossociais e físico-morais - como diz Duarte (1986) - de compreensão da experiência do mal-estar. 
FCLAR, assim como pela Secretaria de Saúde da cidade de Araraquara e também pela equipe de profissionais do CAPS II. Durante todo o trabalho de campo, solicitou-se consentimento - de forma oral - aos participantes para com a pesquisa. No caso das entrevistas, usou-se o Termo de Consentimento Livre e Esclarecido (TCLE). Saliento que os nomes dos interlocutores neste texto são fictícios. Faço isso como forma de proteger seu anonimato, condição necessária para a realização da pesquisa.

\section{Apresentando o campo: o Centro de Atenção Psicossocial II de Araraquara}

O Centro de Atenção Psicossocial II “Dr. Nelson Fernandes” é um serviço de saúde pública, ligado à prefeitura municipal de Araraquara, sob gestão da Gerência de Saúde Mental e da Secretaria Municipal de Saúde da cidade, voltado ao atendimento de pessoas com transtornos mentais graves, assistindo aqueles diagnosticados como psicóticos (pessoas que apresentam alucinações visuais e/ ou auditivas e delírios). A partir de setembro de 2017, começou a atender pessoas com ideação suicida (aquelas que, de forma recorrente, atentaram ou planejaram contra a própria vida). Funciona das $7 \mathrm{~h}$ às $17 \mathrm{~h}$, de segunda-feira a sexta-feira, exceto aos feriados. É parte dos equipamentos em saúde mental de Araraquara, junto ao Centro de Referência de Saúde Mental Adulto - CRASMA, ao Centro de Atenção à Criança - Espaço Crescer, ao Centro de Referência do Jovem e do Adolescente - CRJA, e ao Centro de Atenção Psicossocial Álcool e Drogas - CAPS AD. Além desses serviços públicos, existe uma parceria por meio do SUS com o Hospital Caibar Schutel para internações de usuários quando estão naquilo que é chamado de crise - estão em surto, não querem tomar medicação e podem colocar em risco tanto as próprias vidas como a daqueles com quem convivem.

O CAPS atende tanto demanda espontânea - pessoas que procuram a instituição diretamente sem consulta ou encaminhamento prévio realizado por uma instituição de saúde -, como também aceita os encaminhamentos - que acontecem quando os profissionais de outros serviços de saúde direcionam os sujeitos atendidos para o CAPS II. Sua equipe de profissionais é composta por quatro psicólogos, três terapeutas ocupacionais, cinco técnicas de enfermagem, uma assistente social, uma farmacêutica e uma assistente administrativa, que estão diariamente presentes na instituição, além de uma médica psiquiatra.

A entrada de um novo usuário no serviço dá-se pela chamada triagem, ou primeiro acolhimento, processo em que o possível novo usuário, junto de um familiar ou responsável, é acolhido no serviço, escutam-se suas queixas - categoria usada pelos técnicos para se referir às experiências que justificariam o seu atendimento em um serviço de saúde mental -, história de vida e os motivos de terem procurado o CAPS II. Concluída a triagem, informa-se, na reunião de equipe - realizada diariamente -, a inserção do novo usuário no serviço.

Após a entrada no serviço, aponta-se um dos membros da equipe como técnico de referência para o usuário, geralmente o mesmo que realizou a triagem para a entrada no serviço. O técnico de referência é o profissional responsável pelo caso, que detém a maioria das informações sobre esse usuário, como os grupos 
de que participa, os dias em que vai até a instituição, quem o acompanha, quando tem consulta com as médicas e demais informações, constituindo uma mediação institucional entre usuário, família e o tratamento oferecido pelo CAPS. Quando é necessário resolver alguma questão com o usuário e seus familiares, é esse técnico que marca a chamada "referência", que consiste em uma reunião com os envolvidos no tratamento, para discutir problemas específicos, ou para reavaliação do chamado Projeto Terapêutico Individual ${ }^{5}$. Dentre os profissionais do CAPS II, quando querem saber de alguma informação mais específica de algum usuário ou necessitam de alguma ação mais individualizada, contatam o técnico de referência para saber como proceder ou pedir para que ele tome as ações que achar necessárias.

Caso seja considerado que aquele que passou pela triagem deva receber a terapêutica do CAPS, o mesmo é incluído, ou seja, partir de então é considerado usuário do serviço. Espera-se, assim, que participe das atividades oferecidas pela instituição conforme um projeto terapêutico desenvolvido individualmente, com a mudança de atividades conforme as possibilidades do usuário - quantidades de dias e horários em que consegue comparecer até o CAPS -, seu estado atual de saúde mental e considerações sobre algumas questões externas, como, por exemplo, entrada em um emprego ou gastos com deslocamentos até a instituição. Junto à inclusão do usuário no serviço, também é feita a inclusão de um familiar no grupo de apoio familiar de entrada.

A partir disso, verifica-se a chamada adesão ao serviço, ou seja, o quanto o usuário e seu familiar efetivamente participam das atividades em que foram inclusos. Para que sejam atendidos na consulta psiquiátrica, é necessário que tenham o que é chamado de elevada adesão ao serviço, participando das atividades conforme o previamente combinado e justificando as faltas antecipadamente. Caso se entenda que o usuário e seu familiar não estão comparecendo ao serviço como acordado, a consulta psiquiátrica não é realizada.

Os chamados familiares ${ }^{6}$ - como são denominados pelos técnicos da instituição - são pessoas que, de modo geral, têm alguma relação de parentesco com os usuários do serviço. Podem ser mães, pais, irmãos, filhos, primos, maridos, esposas, sobrinhos e demais pessoas que convivam com aqueles que estão sob tratamento. Espera-se deles que participem das atividades da instituição, cumpram com o que foi proposto no projeto terapêutico dos usuários e ajudem em suas atividades diárias quando necessário, como quando se faz uso de remédios durante o período da noite. Como os técnicos entendem que os familiares são importantes - assim como responsáveis - pelas terapêuticas desenvolvidas no CAPS II, realizam-se grupos na instituição com o intuito de sensibilizá-los ao tratamento dado aos usuários.

Os grupos de apoio familiar - também chamado de grupo de familiares no cotidiano da instituição - ocorrem geralmente em um espaço mais ao fundo do prédio, em uma área coberta ao lado de um pequeno pátio, com cadeiras distribuídas em círculo. Exclusivamente para familiares, o grupo acontece simultaneamente a outro, realizado por outros técnicos apenas com os usuários do serviço. Com o intuito de aproximar os familiares dos usuários do tratamento, são realizados em
5 Projeto Terapêutico Individual (PTI) é o projeto terapêutico desenvolvido para cada usuário, que estabelece em quais atividades participará e quais as suas demandas de cuidado.

6 Familiares, usuários e técnicos/profissionais constituem categorias que podem não abarcar a totalidade das experiências desses sujeitos nas instituições de saúde, tanto porque a "presença" em uma categoria não impede que se possa pertencer a outras, assim como as práticas e discursos presentes na instituição se fazem além e aquém destas, como abordam (Andrade; Maluf, 2017) e (Dias, 2000). Entretanto, optamos por manter essas denominações uma vez que nosso recorte tenta analisar como os sujeitos denominados familiares são acionados nas práticas institucionais para que "aprendam" o que é doença mental. 
dias e horários específicos na semana, com divisões conforme a especificidade de quem é atendido no grupo, assim como do problema de saúde que o usuário do serviço apresenta. Por ocasião da pesquisa, dividiam-se em três, sendo estes os grupos de entrada, os grupos quinzenais e mensais e o chamado grupo de familiares especial.

O grupo de entrada direciona-se especialmente para os familiares dos usuários que entraram há pouco tempo no serviço. Geralmente, após alguns meses, com a estabilização do quadro do paciente e maior tempo de presença nos grupos e nas atividades da instituição, os familiares dos usuários são encaminhados para os grupos quinzenais e mensais. Já o chamado grupo de familiares especial surge da necessidade do serviço de particularizar o atendimento para os familiares dos usuários que apresentam conduta ou ideação suicida, de modo que, dos grupos etnografados, este é o mais recente, tendo iniciado suas atividades a partir de abril de 2018.

Os familiares são alocados para grupos determinados conforme estado de saúde do usuário e dias em que podem comparecer a instituição. Cada grupo é destinado para 30 a 40 pessoas, sendo que, no dia a dia da instituição, o que se observa é a presença em média de 10 a 15 pessoas. Os profissionais que coordenam o grupo conferem a presença dos familiares em uma lista e anotam as respectivas presenças e faltas nos prontuários dos usuários. Caso a psiquiatra observe que os responsáveis não estão comparecendo ao grupo, a consulta com o usuário é desmarcada até que se entre em contato com a instituição. Quando da realização do trabalho de campo, alguns familiares mostravam-se mais presentes do que outros - que apareciam poucas vezes por mês. Além disso, mesmo com a divisão em grupos específicos, havia certa diferença de tempo de participação no CAPS nos grupos, com alguns familiares de recente contato com a instituição junto a outros que já participavam há mais tempo.

O grupo consiste em uma roda de conversa, na qual os participantes, incentivados pelos profissionais do CAPS II, falam de suas experiências diárias no cuidado dos usuários, com a intervenção dos técnicos conforme a necessidade. Os assuntos abordados abrangem uma variedade de temas relacionados à convivência com os usuários do serviço, em um diálogo construído por meio das interações entre os presentes, quer entre técnicos e familiares, quer entre os familiares presentes. Assim, discorrem sobre temáticas diversas, como o uso das medicações, expectativas em torno do tratamento, o que é transtorno mental, dificuldades cotidianas na convivência com alguém com sofrimento psíquico intenso. Nesse contexto, é função dos técnicos fazer intervenções pontuais sobre as temáticas debatidas - como problematizar algum aspecto da discussão e "devolver" a fala para os familiares, ou dar alguma informação de caráter mais técnico sobre os transtornos mentais -, além de observarem o horário, para que o grupo de familiares não se estenda além do planejado e afete outras atividades.

Esse momento de diálogo - mesmo que assimétrico, uma vez que os técnicos interpretam que conhecem a "realidade" da "doença mental" e os familiares ainda a estão "descobrindo" - mostra-se fundamental tanto para a fidelização dos familiares às práticas e discursos do CAPS II quanto para posterior apropriação 
destas práticas. Isso porque, por meio da fala em grupo, os familiares explicitam seus saberes e perspectivas sobre o mal-estar, o que permite que os profissionais direcionem suas práticas para a solução dos problemas trazidos por estes agentes, fidelizando-os às práticas institucionais.

Quando um novo familiar aparecia, devido à entrada de um novo usuário no serviço, os técnicos que coordenavam a reunião, em especial os de nível superior, apresentavam o grupo, diziam qual era sua finalidade e objetivos, muitas vezes pedindo para familiares de usuários que eram atendidos há mais tempo explicarem para que servia ou dizerem em que a participação no grupo lhes agregava ${ }^{7}$.

Geralmente, quando era a primeira vez que um familiar falava no grupo, contava o itinerário que tivera até chegar ao CAPS. Às vezes remetendo à infância, falava desde quando observou um problema, como buscaram ajuda, com quem falaram, e o que já haviam tentado para resolver a situação. Na maior parte dos casos, os familiares chegavam até o CAPS durante o que é chamado de surto, quando o usuário começava a apresentar um comportamento que não compreendiam ou com o qual não conseguiam lidar. Houve casos em que foi uma fala desconexa em relação ao contexto da casa que levou os familiares a procuraram ajuda médica; em outros, foi uma recusa a se alimentar; também ocorre de perceberem como início de um comportamento problemático o fato de os usuários saírem de casa sem destino certo e ficarem por dias ou até semanas nas ruas.

Observei que existia um forte recorte de gênero quanto aos membros que mais participavam enquanto familiar de usuário na instituição. Eram, geralmente, mães, avós, tias, irmãs ou esposas que se responsabilizavam pela vinda e pelos contatos com a instituição; quando homens, frequentemente eram os maridos que apareciam nas reuniões, contando também com alguns pais de usuários. Os profissionais percebiam essas recorrências e comentavam de modo "crítico" sobre a responsabilidade de toda a família no cuidado e no tratamento, fazendo uma observação positiva quanto à presença de um familiar - geralmente homem - que começasse a comparecer ao grupo. Outro fator importante é a classe social, uma vez que a maior parte dos usuários do serviço era de pessoas economicamente desfavorecidas, que muitas vezes residiam em regiões mais periféricas da cidade e não tinham meios de locomoção a não ser ônibus. Dessa forma, era uma constante ouvir dos técnicos da instituição que familiares ligavam para avisar que estavam sem condições de irem até o CAPS II devido à falta de dinheiro para a passagem de ônibus.

Ao final das reuniões dos grupos de familiares, os técnicos da instituição anotam o que foi dito dos usuários por seus familiares em seus respectivos prontuários, assim como anotam as faltas justificadas ou o não comparecimento do familiar. Caso vejam como necessário, levam o que foi dito sobre o usuário à próxima reunião de equipe, para que sejam tomadas providências, como conversar com a psiquiatra sobre a medicação prescrita, a inclusão do usuário em mais ou menos atividades, a necessidade de uma referência, ou até mesmo a revisão do projeto terapêutico individual.

Iniciando-se por volta das $11 \mathrm{~h}$ e indo até as $12 \mathrm{~h}$, a reunião de equipe acontece
7 Nesse tipo de situação, eu também aproveitava para me identificar, falar porque estava ali e pedir permissão aos presentes para participar da reunião e de demais outras em que estivessem presentes. 
diariamente no CAPS II. É realizada com o intuito de informar a todos da equipe sobre o estado de alguns dos usuários ou de informar a entrada de um novo integrante após a triagem, assim como é também o momento em que comunicam faltas a serem abonadas, discutem a organização das atividades do serviço e a realização dos eventos da instituição, como passeios ou festas.

A reunião começa com um dos técnicos falando sobre alguma triagem que realizou e sobre a inclusão do novo usuário no serviço. Caso existam dúvidas sobre qual seria o serviço de saúde para o possível usuário - na visão daquele profissional que realizou a triagem -, discutem em equipe se o usuário ficará no CAPS ou para onde o encaminharão. Ou então se fala de um plantão e de alguém que havia aparecido solicitando atendimento.

Muitas vezes, presenciei falas recém-proferidas no grupo de familiares serem trazidas pelo profissional que coordenava o grupo e levadas ao técnico de referência do caso. Se é percebida a necessidade de alguma providência em relação ao que foi relatado, discutem-se as ações que podem ser tomadas, como inclusão em uma ou mais atividades por mais dias, discussão do caso com a médica psiquiatra da instituição ou a justificativa de acionar algum familiar para que algo fosse realizado em sua casa. A reunião também é um espaço de organização das atividades dos técnicos, em que discutem como cobrir determinadas atividades durante a falta abonada de um membro, alternar períodos entre técnicos de mesma profissão durante um dia ou outro, organizar quais funcionários cumprirão horas extras e passar comunicados da secretaria de saúde e da gerência de saúde mental.

Entretanto, as considerações e conversas não ocorrem apenas durante reunião: por várias vezes observei que os técnicos constroem suas percepções sobre os usuários e planejamento das ações posteriores em momentos não institucionais, geralmente após algumas atividades ou durante intervalos. Desta forma, não era raro ver os técnicos conversando sobre algum usuário ou familiar na cozinha, espaço das pausas diárias.

Durante o período do trabalho de campo na instituição, não houve resistência ou impedimento para com as investigações por parte dos técnicos ou familiares. Por vezes, quando perguntava aos profissionais o que estavam fazendo, respondiam de forma pedagógica, tentando explicar ponto a ponto os motivos de suas práticas, muitas vezes fazendo referência à sua formação: por exemplo, quando perguntei sobre personalidade - conceito muito utilizado pelos profissionais da instituição - um dos psicólogos apresentou-me uma fotocópia do Cadastro Internacional de Doenças (CID), impresso na forma de um livreto. Explicou que personalidade "é a forma como lidamos" - advertindo que sua definição foi simplificada para que eu entendesse.

Muitos dos outros episódios em que eu perguntava sobre o funcionamento das rotinas institucionais ocorriam dessa forma: traziam exemplos, falavam sobre normas e regras existentes, davam suas opiniões, tentando inserir-me naquele contexto. Quanto aos familiares, sempre que possível tentei uma aproximação, conversando, no intuito de apreender como eles vivenciavam a passagem pela instituição. Entretanto, não havia muito tempo para conversar com eles, exceto em 
alguns momentos, como antes do início de uma reunião de familiares ou algum tempo depois do final desta, de modo que foi idealizado o recurso da entrevista.

\section{Os familiares no CAPS II: os grupos de apoio e seus impactos nas práticas em saúde mental}

Realizo, no presente tópico, uma análise do grupo de familiares enquanto um espaço de troca de experiências e saberes em saúde mental, e dos efeitos que a participação no grupo produz em suas práticas e discursos.

Como colocado anteriormente, os encontros dos grupos acontecem três vezes por semana, variando conforme os diagnósticos dos usuários com quem estes familiares têm relações, assim como seu tempo de permanência na instituição e estado de saúde. Por exemplo, caso um usuário - ao passar pela triagem - seja diagnosticado como sicótico $^{8}$, seu respectivo familiar é incluso no grupo realizado às segundas-feiras, na parte da manhã. Caso o usuário seja diagnosticado como neurótico, o familiar é incluso nos grupos de terças-feiras à tarde. As categorias neurótico(a) e psicótico(a), utilizadas pelos técnicos para descrever o estado de saúde dos usuários e para organizar as atividades em que estes participariam não costumam ser usadas durante as reuniões de grupo, apenas nas conversas entre os profissionais e nas que tive com eles; nos grupos, os profissionais justificavam a separação em grupos de familiares diferentes devido às demandas e dificuldades que existiriam para cada caso particular, sem propriamente se referir aos termos médicos de forma explícita.

O grupo é realizado pelo diálogo entre os presentes, sendo composto exclusivamente por técnicos do CAPS II e familiares dos usuários da instituição. Os técnicos iniciam a discussão, abordando algum tema específico, avisando sobre algum evento que ocorrerá no CAPS ou perguntando aos presentes sobre a rotina de suas casas. Caso alguém se sinta afetado sobre algum ponto do assunto que está sendo discutido, a pessoa manifesta-se, e os profissionais da instituição fazem considerações pontuais caso não concordem ou queiram esclarecer alguma questão pertinente. $\mathrm{O}$ objetivo do grupo, segundo os profissionais que o coordenam, é a troca de experiências sobre o cuidado em saúde mental, temática que é discutida a partir da vivência dos familiares. Assim, nesse jogo dialógico entre seus participantes, decorrem todos os grupos, desde seu início até o horário final de sua duração.

Pude observar que os familiares se reconhecem nas experiências uns dos outros a partir das dificuldades e angústias do cotidiano com os usuários que mostravam recorrentes, como a sensação de impotência e a sobrecarga trazida pelo cuidado de alguém que é portador de transtorno mental grave. Por diversas vezes, expressões como "meu problema não é tão grande perto do dele(a)" aparecem na fala dos presentes nos grupos. Alguns comparam a própria situação familiar com a de outros que ali estão, dizendo que, ao participarem do grupo, perceberam que aquilo que levavam como um sofrimento por demasiado solitário e único, é algo em certa medida compartilhado, mais grave até em outros casos. Por exemplo, um dos familiares presentes, cuja esposa tem episódios de ideação suicida recorrente e apresenta, segundo ele, grandes oscilações de humor, disse que, ao ouvir
8 Neurótico e psicótico são classificações utilizadas pela equipe do CAPS II para se referir ao tipo de sofrimento específico que cada usuário apresenta; quando questionados sobre as definições, um sujeito psicótico se diferencia de um sujeito neurótico devido à presença de alucinações - impressões auditivas e visuais não perceptíveis às outras pessoas no mesmo contexto - e delírios - que seriam crenças fantasiosas sobre a realidade, também não compartilhadas por outros indivíduos em um mesmo contexto. 
a história de outra familiar que estava ali - a qual tinha um filho esquizofrênico e alcoólatra, que tentava sair durante a noite para conseguir bebida - passou a pensar que seu sofrimento não seria tão grande quanto o dela.

Quando os familiares traziam em suas falas crenças religiosas sobre saúde mental, os técnicos procuravam estabelecer os limites do elemento religioso na terapêutica do usuário, para que não abandonassem a instituição. Como nesse diálogo que ocorreu durante a realização de um grupo de famílias, entre Olga e a psicóloga que estava a coordenar o grupo. Olga é mãe de uma usuária que estava há aproximadamente dois meses no CAPS II e mostrava-se preocupada com as saídas da filha. Um pouco antes, outra familiar relatou que seu filho não saía de casa, o que piorava seu estado de saúde. Essa fala instigou os presentes a discutirem se não sair de casa piorava o estado de saúde mental dos usuários. Nesse contexto se insere a situação descrita a seguir.

Olga diz que a filha sai de casa e chega tarde, toma o remédio tarde e não dorme. A psicóloga pergunta se ela acha que o passeio foi bom. Diz que o remédio tem que ser tomado conforme as atividades do usuário, não mudar as atividades para tomar remédio (Dá exemplo do antibiótico que se toma às $6 \mathrm{~h}$ e às $18 \mathrm{~h}$, para respeitar as doze horas de intervalo).

Olga: Minha filha começou a ir na Igreja, coisa que não fazia há tempo.

Psicóloga 1: Ela está gostando? Só não pode agora falar que Deus salva e deixar de tomar o remédio. 0 bom é oração mais remédio.

Observa-se que a fala da psicóloga busca acomodar a prática religiosa da filha de Olga dentro dos cuidados oferecidos pela instituição - em especial, o uso de medicações - sem que a religião se faça proeminente, apontando para um caminho intermediário, em que "o bom é oração mais remédio".

Nesse sentido, os técnicos buscam trabalhar sobre o cuidado e seus significados durante a realização do grupo de familiares. A partir do que é falado pelos familiares, o responsável pelo grupo tenta acolher a fala do presente e direcioná-la, problematizando alguns aspectos em função das terapêuticas da instituição, no intuito de instrumentalizar as práticas cotidianas dos familiares para lhes inculcar modos de agir que estivessem de acordo com as normas éticas do CAPS II e do processo de desinstitucionalização da reforma psiquiátrica. Embora eficaz para com alguns dos presentes - que então interpretavam suas ações cotidianas de cuidado de novo modo, o que se tornava explícito quando diziam que haviam "aprendido" a cuidar e a conviver com os sujeitos adoecidos - outros se mostravam resistentes, como a presença do termo sem-vergonha dito pelos familiares, que interpretavam o mal-estar de forma diferente das institucionais.

Por exemplo, durante uma das reuniões de que participei, percebi que a psicóloga usou o termo "cabeça" para falar da subjetividade de um dos usuários que não queria tomar o remédio psiquiátrico, categoria utilizada constantemente pelos 
familiares para se referir a uma parte do funcionamento intelectual e moral dos sujeitos. No contexto a seguir, a familiar afirma ter dado um sal de frutas para o filho, que estava mal do estômago e, devido a isso, ele não quis tomar o remédio psiquiátrico. A psicóloga tenta acalmar a mãe e orientá-la de modo que ela pudesse convencer o filho a tomar o remédio. Registrei essa conversa da seguinte forma em meu caderno de campo:

Psicóloga 1: Fala para ele que o estômago não está bom, mas a cabeça está boa. Ele já ficou seis meses na clínica [para usuários de drogas]. Será que ele vai querer voltar?

Familiar: Eu falei isso para ele. Mas depois ele tomou.

Psicóloga 1: Fala para ele o quanto ele é importante para a família. Que não é um estorvo.

Nesta situação, o uso do termo "cabeça" pela técnica para se referir à fala da mãe, é uma das estratégias utilizadas para conhecer a forma como os familiares pensam a subjetividade e tentar construir um campo comum de diálogo. Muito do que os técnicos falavam consistia em uma tentativa de fazer com que os cuidados que os familiares direcionavam a seus entes ocorresse de uma forma específica, com a aplicação regular da medicação, a das atividades do CAPS II, a presença nas consultas e demais recomendações que a instituição faz aos usuários e familiares.

Outro ponto importante é que os técnicos incentivam os familiares a aderirem a uma postura que não julgue moralmente os comportamentos do usuário e que, ao mesmo tempo, leve a um comprometimento pessoal do familiar para com o tratamento dos transtornos mentais. Assim, por diversas vezes surgiam alguns debates por parte dos familiares se os comportamentos que os usuários apresentavam seriam resultado de alguma "sem-vergonhice" ou se seria doença. Nesses momentos, os técnicos tentavam intervir, explicando que aquilo que parecia uma "falha moral" dos usuários - desatenção quanto a regras domésticas, xingamentos etc. - era, na verdade, sintoma de uma doença e, por isso, algo que necessitaria de uma postura que evitasse realizar julgamentos morais, conforme seria feito com doenças crônicas fisiológicas, como o diabetes ou a pressão alta. Deste modo, exigia-se uma postura eticamente compromissada com a terapêutica oferecida na instituição, o que consistia em relatar todos os sintomas e demais informações do usuário que fossem entendidas como relevantes à equipe, oferecer a medicação regularmente para a prevenção do surto, comparecer à instituição regularmente, ter uma postura paciente para com o usuário, além de oferecer constantes atividades que incentivem a autonomia do usuário - chamadas de estímulos pelos técnicos da instituição. Geralmente, quando esta postura de não julgar era colocada em questão pela família, os técnicos intervinham diretamente, contestando ou problematizando, ou então pediam a algum dos presentes para que falassem de suas experiências pessoais no cuidado. 
Os familiares discutiam entre si durante a realização do grupo sobre a possibilidade de responsabilização moral dos usuários, avaliando tanto a partir de suas trajetórias pessoais - aquilo que tinham vivido, e por isso, tinham experiência quanto pela história de vida daqueles por quem eram responsáveis. Pude observar que quando avaliavam que o mal-estar do usuário não seria legítimo em relação às oportunidades que estes tiveram em suas vidas, os familiares lançavam mão da expressão "sem-vergonha" ou "sem-vergonhice", para falar de alguém que deixava de cumprir com suas obrigações cotidianas sem aparente justificativa.

Pude observar uma reunião em que um dos familiares presentes dizia que o problema de seu irmão - usuário do CAPS II - era "uma mistura de loucura com sem-vergonhice", já que ele sabia que caso não cumprisse suas obrigações com a casa - como limpar a sujeira que fez -, alguém o faria. Além disso, disse que seria estranho, ele, enquanto irmão mais novo do usuário, dar "remédio na boca de um velho", que era o irmão mais velho. $O$ técnico que organizava o grupo disse-lhe para considerar o que estava dizendo e convidou outros presentes a se manifestarem a favor ou contra. Mesmo quando um dos presentes concorda que "às vezes é doença; às vezes é sem-vergonhice", o técnico continua problematizando o discurso do familiar, incentivando-o a pensar em outras estratégias de cuidado caso não possa - ou não queira - responsabilizar-se pelos cuidados do irmão. Pude notar que as falas dos profissionais não são acatadas de forma unívoca: em alguns casos, reforçava-se a fala dos técnicos, concordando e dando exemplos; em outros, ela era questionada. Não raro, presenciei que nos grupos ocorriam divergências, não entre técnicos e familiares, mas dos familiares entre si.

A orientação dos técnicos muitas vezes se refletia na forma como os familiares dos usuários lidavam com seus parentes dentro do contexto familiar, reproduzindo a dimensão "pedagógica" presente nas práticas e nos discursos dos técnicos do CAPS. Dessa forma, quando ocorriam conflitos em relação ao comportamento do usuário, muitas vezes os familiares que frequentavam a instituição tomavam para si o papel de mediadores, dialogando com outros familiares que não participavam das reuniões, procurando informá-los sobre o que seria doença mental e como deveriam agir em relação ao usuário. Não raro, os familiares dos usuários presentes no grupo de famílias apontavam que algum outro começou a "entender também" a situação, deixando de pensar que era "sem-vergonhice".

Os profissionais tentavam constantemente traduzir os discursos dos familiares sobre o que era doença mental para seus repertórios técnicos, ao mesmo tempo em que tentavam diminuir a importância da experiência religiosa sobre a doença mental; por outro lado, os familiares traziam suas experiências cotidianas com os usuários, perguntavam sobre como se poderia entender determinado comportamento. Essa possibilidade de construção de discursos compartilhados entre profissionais realizava-se com em base em interesses que, mesmo que diversos, se encontravam de modo complementar: por um lado, os familiares supriam a necessidade dos técnicos sobre informações quanto aos usuários, assim como avaliavam a eficácia e a adesão do usuário ao tratamento; por outro, recebiam orientações de caráter prático - sobre como proceder em determinadas situações de conflito, 
de que modo agir durante um período de crise.

Entendo que a participação na instituição pode ser interpretada por meio do conceito de mediação intercultural, de Montero (2006). A autora, problematizando o estatuto antropológico da diferença, parte do que denomina como interpenetração de civilizações, ou seja, o processo de convergência entre horizontes simbólicos de grupos diferentes que coexistem em um mesmo universo de relações. Para isso, escolhe como objeto de estudo as missões jesuítas, dado que, por sua própria condição de operacionalização, estas revelam um momento histórico em que houve contato efetivo entre dois coletivos sociais diferentes, os jesuítas e as populações indígenas da América do Sul. Segundo Montero, nota-se que, nesse encontro, foram produzidas estratégias de demarcação simbólica das formas de pertença e de construção da alteridade, tanto pelos missionários que procuravam incorporar as populações nativas às relações coloniais quanto por parte dos indígenas, que também tentavam incorporar a situação de contato para seus repertórios locais. Assim, para dar conta das lógicas práticas investidas na construção de um sentido compartilhado entre esses grupos, Montero (2006) formula o conceito de mediação intercultural.

Esse conceito alude às formas compartilhadas de construção de sentido: "a ênfase se põe, pois, nas lógicas práticas investidas nessas relações e em seu modo de agenciar os sentidos para produzir um acordo circunstancial sobre a ordem do mundo cujo formato não pode ser antecipado de antemão" (Montero, 2006, p. 23). Fazendo referência a Bourdieu, Montero destaca o conceito de poder simbólico enquanto categoria analítica para se pensarem as relações entre construção de linguagem e realidade social: as nomeações e classificações que surgem desses encontros entre agentes sociais têm uma intenção performativa, ou seja, procuram produzir realidades sociológicas específicas a partir de um contexto de práticas sociais compartilhadas.

Deste modo, a construção de um campo comum de práticas e representações, em que se pode repensar o que é transtorno mental e a pertinência de sua atenção em uma instituição de saúde é a estratégia dos profissionais do CAPS II de Araraquara para aproximar os familiares dos usuários do projeto terapêutico, sem que descumpram com o que foi acordado. Assim, por exemplo, as concepções religiosas que são relatadas pelos técnicos como um dos maiores entraves à terapêutica do CAPS são incorporadas, na prática do grupo de familiares, enquanto elemento pertinente ao tratamento, mas que não pode adquirir centralidade em face dos aspectos médicos e psicossociais. Logo, não raro veem-se os técnicos argumentando que as práticas religiosas não são em si problemáticas no cuidado da doença, mas o são quando assumem papel central, o que causaria o abandono da medicação recomendada.

Portanto, o esforço das ações dos técnicos sobre os familiares direciona-se para os significados do que é cuidar: procura-se a todo momento incutir nos familiares que as atividades da instituição têm finalidade terapêutica, que devem ser cumpridas para que os usuários melhorem seu estado de saúde. Nesse sentido, procura-se acolher as preocupações dos familiares sobre o tratamento promovido enquanto os fidelizam às práticas institucionais. 


\section{Os familiares em seus lugares: a reapropriação das práticas de cuidado em outros contextos}

Pretendo, neste tópico, analisar como as práticas e discursos sobre saúde mental produzidas nas relações entre familiares e profissionais do CAPS II se desenvolvem em torno de disputas e tensões sobre as formas como estas mesmas práticas e discursos serão apropriados como processos de subjetivação.

No contexto do CAPS II, os discursos e as ações dos técnicos visam inculcar nos familiares os valores da instituição, procurando influenciar suas práticas cotidianas de cuidado, a relação entre usuário e familiar, além da relação entre familiar e instituição. As interações entre equipe técnica e familiares fomentam determinados tipos de subjetividade que estejam de acordo com as normativas éticas que regem as práticas dos profissionais. Como apontei anteriormente, um dos principais objetivos dos profissionais envolvia incentivar uma postura moralmente neutra, porém pessoalmente comprometida com o tratamento dos transtornos mentais e as práticas de cuidado fomentadas na instituição. Nesse sentido, espera-se que a convivência cotidiana com a instituição leve a determinado modo de se pensarem e se entenderem os transtornos mentais.

Presenciei, em uma das reuniões dos grupos de familiares, um dos técnicos advertindo aos presentes sobre suas responsabilidades no cuidado dos usuários. Reproduzo sua fala a seguir:

Psicólogo 2: Tem pessoas que tem dois quadros mentais: gente que se isola e gente que fica agressivo. Tem dois tratamentos: brincar de tratar ou levar a sério o tratamento. A gente precisa da família. 0 tratamento só foi para a frente quando a gente pegou no pé da senhora [referindo-se a uma das presentes que começou a se envolver mais com as atividades da instituição após maior pressão dos técnicos].

Psicólogo 2: A gente tem as mesmas responsabilidades que vocês. Somos chão de fábrica. 0 paciente fica 1 h30 aqui, e fica $24 \mathrm{~h}$ com vocês.

Em alguns casos, essa postura é prontamente incorporada, como pude perceber durante uma entrevista com Fernanda, mãe de Caio, que estava frequentando as reuniões do CAPS há três meses. Quando perguntei sobre seguir as recomendações dos profissionais do CAPS em seu cotidiano, Fernanda me disse que achava o trabalho dos profissionais da instituição fundamental, e se mostrava indignada com - conforme ela entendia - a falta de comprometimento de alguns dos familiares que frequentavam o grupo. Como afirmou sobre a necessidade de cooperar com o serviço de saúde:

Fernanda: O CAPS faz um puta daquele trabalho, chega em casa a mãe não dá o remédio pro filho? Daí o filho vai sair pro bar, pra sair pra beber? Como assim? Você está em tratamento, você não pode sair pra beber. Eu acho assim. 0 trabalho que o CAPS fez vai tudo pra água abaixo. Do que adianta? 
Percebe-se que a instituição espera que os familiares dos usuários cooperem com informações sobre os usuários e suas histórias de vida. Se, como apontou Sartori, (2011) sobre o CAPS III em Campinas, neste tipo de serviço psicossocial constantemente se produz um saber sobre o usuário, que circula entre os técnicos, no CAPS II de Araraquara os familiares são chamados a participar deste processo mediante os contatos com a instituição, enquanto atores necessários para a construção e atualização dos saberes dos profissionais sobre aqueles que se utilizam de seus serviços. Desta forma, espera-se que tudo aquilo que envolva a saúde do usuário seja repassado à instituição para que possam reavaliar suas ações ou mantê-las, refinando o saber produzido sobre ele. Neste sentido, a incorporação dos familiares ao projeto terapêutico permite que a instituição mantenha determinado controle de como o usuário vive e age fora dela, em especial sobre o que este faz em relação ao projeto terapêutico desenvolvido no CAPS quando não está sob sua tutela.

Nesse sentido, as interações entre familiares e técnicos do CAPS II resultam em, por um lado, esforço de criação de uma linguagem comum sobre a doença mental, em que as categorias nativas sobre desordem subjetiva - como depressivo/a, nervoso/a, mal da cabeça - ganham novos significados, e a ideia de doença mental enquanto fenômeno médico - e consequentemente, de competência médica - começa a ser incorporada; por outro lado, observa-se certa tensão presente entre as apropriações possíveis dos familiares e os objetivos institucionais, que visa adequar as práticas de cuidado para com os usuários sigam as normativas da instituição. Nota-se que há uma disputa pela forma que os saberes e as práticas médicas veiculadas no CAPS II serão apropriados, em que tão importante quanto a criação de discursos e práticas comuns, espera-se que os familiares também compartilhem - mesmo que não totalmente - das normativas éticas que perpassam as relações entre usuários e técnicos.

Como apontam Cohn (1989) e Fleury (2009), o Sistema Único de Saúde (SUS) é consolidado mediante um processo político em luta pela garantia do direito à saúde enquanto direito dos cidadãos e dever do Estado, em que a tensão entre os interesses privados e públicos se faz presente. Deste modo, espera-se que por meio da participação cidadã ativa neste tipo de políticas - não apenas enquanto usuários, mas como agentes sociais com capacidade de decisão e ação - se possa democratizar o direito à saúde, impedindo que seja tomado por interesses contrários à saúde pública ou se reduza a uma institucionalização excessiva e de pouco efeito. Para isso, é necessário que esse processo afete não apenas as instâncias formais, mas seja capaz de fomentar subjetividades alinhadas com práticas políticas que visam justamente à construção desse espaço público.

\section{Considerações finais}

As ações dos técnicos do CAPS II de Araraquara têm por objetivo incluir os familiares nas práticas institucionais, de modo que estes façam parte do projeto terapêutico e político promovido pela instituição. Para isso, procuram mediar os significados e as representações que os familiares dos usuários trazem sobre 
o que é doença mental e como deve ser esse cuidado, procurando diferenciar a doença mental, enquanto categoria veiculada pela instituição, da categoria de sem-vergonhice, utilizada pelos familiares para se referir a uma característica moral daqueles que não querem cumprir para com suas obrigações cotidianas, ou de outras formas de valoração moral da conduta dos usuários da instituição.

Entretanto, enquanto familiares, aqueles que têm relações de parentesco para com os usuários da instituição formam um grupo um tanto heterogêneo, seja quanto a práticas mobilizadas para cuidar do usuário assim como a teorias próprias que elaboram para tentar entender o que seus parentes têm. Mesmo que frequentemente se observe que as famílias eram originárias dos estratos mais economicamente carentes da cidade, isso não levava a concepções iguais ou similares sobre o que são os transtornos mentais ou quais as suas causas e seus tratamentos.

Nervoso, cabeça ruim e mal da cabeça eram expressões que os familiares usavam de forma constante para se referir às diversas formas de mal-estar presentes em seu cotidiano. Como mostra Cardoso (1999), estas formas de classificar a experiência da desordem subjetiva não podem ser reduzidas aos conceitos de neurose ou psicose - utilizados geralmente entre os técnicos da instituição para classificar os transtornos psíquicos dos usuários -, pois remetem a contexto socioculturais específicos, ligados a determinadas concepções de mente e saúde.

Portanto, nota-se que as populações atendidas pelo CAPS II de Araraquara, enquanto familiares dos usuários, constituem uma população heterogênea, o que resulta em apropriações diversas dos repertórios ético-políticos fomentados pelos profissionais. Deste modo, enquanto processo de mediação intercultural, as práticas, discursos e representações veiculadas na instituição são constituídas na forma de consensos circunstanciais sobre o que é doença mental e os modos de funcionamento da subjetividade, apropriados conforme as particularidades de cada grupo social que é atendido. Entretanto, como os chamados familiares constituem um grupo heterogêneo, a apropriação do que é construído na instituição se dá de modo diferenciado, de acordo com as possibilidades de cada uma dessas famílias: replicar o que é transmitido no CAPS II envolve desejos e condições sociais, familiares e econômicas. 


\section{Referências}

ANDRADE, Ana Paula Müller de; MALUF, Sônia Weidner. Loucos/as, pacientes, usuários/ as, experientes: o estatuto dos sujeitos no contexto da reforma psiquiátrica brasileira. Saúde em debate, Rio de Janeiro, v. 41, n. 112, p. 273-284, 2017. Disponível em:http://www.scielo.br/scielo.php?script=sci_arttext\&pid=S0103-110420170001002 73 \& lng=en\&nrm=iso. Acesso em: 04 nov. 2018.

AMARANTE, Paulo (Coord.). Loucos pela vida: a trajetória da reforma psiquiátrica no Brasil. Rio de Janeiro: Fiocruz, 1995.

CARDOSO, Marina Denise. Médicos e clientela: da assistência psiquiátrica à comunidade. São Carlos: Editora UFSCar, 1999.

COHN, Amélia. Caminhos da reforma sanitária. Lua Nova, São Paulo, n. 19, p. $123-$ 140, 1989. Disponível em: http://www.scielo.br/scielo.php?script=sci_arttext\&pid=S0102-64451989000400009\&lng=en\&nrm=iso. Acesso em: 07 mar. 2019.

DUARTE, Luiz Fernando Dias. Da vida nervosa nas classes trabalhadoras urbanas. Rio de Janeiro: Jorge Zahar, 1986.

FLEURY, Sonia. Reforma sanitária brasileira: dilemas entre o instituinte e o instituído. Ciência \& Saúde Coletiva, v. 14, n. 3, p. 743-752, 2009.

FOUCAULT, Michel. Doença mental e psicologia. Rio de Janeiro: Tempo Brasileiro, 1975.

LOYOLA, Maria Andréa. Médicos e curandeiros: conflito social e saúde. São Paulo: Difel, 1984.

MONTERO, Paula. Da doença à desordem. Rio de Janeiro: Edições Graal, 1985.

MONTERO, Paula. Introdução - Missionários, índios e mediação cultural; Capítulo 1 Índios e Missionários no Brasil: para uma teoria da mediação cultural. In: Deus na aldeia: missionários, índios e mediação cultural. São Paulo: Globo, 2006. p. 9-66.

PRADO, Luiz Ricardo de Souza. Se for karma vai pagar com remédio: representações de doença mental nos centros de atenção psicossocial em Araraquara. Monografia (Bacharelado em Ciências Sociais) - Faculdade de Ciências e Letras de Araraquara, UNESP, Araraquara, 2017.

PRADO, Luiz Ricardo de Souza. Micropolíticas e processos de mediação no atendimento psicossocial: o CAPS II de Araraquara. Dissertação (Mestrado em Ciências Sociais) Faculdade de Ciências e Letras de Araraquara, UNESP, Araraquara, 2019.

SARTORI, Lecy. O manejo da cidadania e a democracia do cuidado. Campos - Revista de Antropologia Social, v. 12, n. 1, p. 85-101, 2011. Disponível em: http://revistas.ufpr.br/ campos/article/viewFile/24076/18782. Acesso em: 30 mar. 2019. 